BRAGANÇA:

UM BRE
SOBRE A RESE

EXTRATIVISTA MARIN

CAETÉ-TAPERA 


\section{BRAGANÇA: UM BREVE OLHAR SOBRE A RESERVA EXTRATIVISTA MARINHA CAETÉ-TAPERAÇU}

\section{ARIADNE DA COSTA PERES CONTENTE}




\title{
BRAGANÇA: UM BREVE OLHAR SOBRE A RESERVA EXTRATIVISTA MARINHA CAETÉ-TAPERAÇU
}

\section{Resumo}

No Pará, encontra-se a REM Caeté-Taperaçu, localizada no Município de Bragança, criada pelo Decreto de 20 de maio de 2005, distante de Belém aproximadamente $210 \mathrm{~km}$. Esta pesquisa objetivou conhecer como estava se dando o processo de implantação desta Unidade de Conservação, considerando a percepção de diferentes atores sociais. A percepção foi distinta em relação a REM, e principalmente os usuários e moradores reforçaram as melhorias obtidas, àquelas relacionadas à concessão dos créditos de fomento. Dentre estes, poucos sabiam o que vinha a ser uma RESEX, bem como desconheciam os instrumentos de gestão. O intercâmbio deficiente de informações no que diz respeito ás regras e ás novas territorialidades propostas por este tipo de UC, fez com que emergisse a necessidade de desenvolver espaços de competência relacionados à partilha de saberes gerados no seio dos atores envolvidos bem como a necessidade do diálogo entre racionalidades e sensibilidades distintas.

Palavras-Chave: Unidade de Conservação, Resex Marinha Caeté-Taperaçu, diálogo.

\section{BRAGANÇA: A BRIEF LOOK AT CAETÉ-TAPERAÇU MARINE EXTRACTIVE RESERVE}

\begin{abstract}
The Marine Extractive Reserve Caeté-Taperaçu is located in the municipality of Bragança, state of Pará, created by Decree of May 20, 2005, 210 Km away from Belém. This research aimed to evaluate the implementation process of this unit, considering the perception of different social actors. The perception of the actors differed in relation to REM, and especially users and residents pointed out the improvements obtained, those related pointed out the improvements obtained, those related to financing by INCRA. Some residentes and users knew what was an extractive reserve and its management papers. The poor information sharing regarding new rules and territoriality, raised the need to develop areas of expertise related to the sharing of existing knowledge on the actors involved, and the need for dialogue between different rationalities and different sensitivities.
\end{abstract}

Keywords: Conservation Unit, Resex Marinha Caeté-Taperaçu, dialogue. 


\section{BRAGANÇA: UNA BREVE NOTA SOBRE LA RESERVA EXTRACTIVA MARINA CAETE-TAPERAÇU}

\section{Resumen}

La Reserva Extractiva Marina Caeté-Taperaçu se encuentra en el municipio de Bragança, estado del Pará, creada por Decreto del 20 de mayo de 2005, lejos de Belén aproximadamente 210 kilómetros. Esta investigación ha tenido lo objetivo de evaluar el proceso de implementación de esta unidad, teniendo en cuenta la percepción de los distintos actores sociales. La percepción de los actores difiere en relación con REM, y en especial los usuarios y residentes señaló las mejoras obtenidas, los relacionados señaló las mejoras obtenidas, las relativas a la financiación por el INCRA. Algunos Residentes y usuarios sabían lo que era una reserva extractiva y sus documentos de gestión. El pobre intercambio de información sobre las nuevas normas y la territorialidad, planteó la necesidad de desarrollar las áreas de especialización relacionadas con la puesta en común de los conocimientos existentes sobre los actores involucrados, y la necesidad de diálogo entre las diferentes racionalidades y diferentes sensibilidades.

Palabras clave: Unidad de Conservación, Resex marina Caeté-Taperaçu, diálogo.

Endereço da autora para correspondência: ICB - Universidade Federal do Pará, Rua Augusto Corrêa, No 1, Cidade Universitária José da Silveira Neto, Guamá, CEP: 66075-110, Belém, PA, Brasil. E-mail: ariadne@ufpa.br 
UNIDADE DE USO SUSTENTÁVEL: AS RESEXS

No Brasil, as áreas protegidas incluem as terras indígenas, território quilombolas e as unidades de conservação integrantes do Sistema Nacional de Unidades de Conservação. Essas se dividem em dois grupos e respectivas categorias de manejo: as unidades de Proteção Integral (Estação Ecológica, Reserva Biológica, Parque Nacional, Parque Estadual, Monumento Natural, Refúgio de Vida Silvestre) e as unidades de Uso Sustentável (Área de Proteção Ambiental, Área de Proteção Ambiental Estadual, Área de Relevante Interesse Ecológico, Floresta Nacional, Floresta Estadual, Reserva de Fauna, Reserva de Desenvolvimento Sustentável, Reserva Particular do Patrimônio Natural e Reserva Extrativista).

Dentre as de uso sustentável, as reservas extrativistas são áreas utilizadas por povos tradicionais cuja subsistência baseia-se no extrativismo e, complementarmente, na agricultura de subsistência e na criação de animais de pequeno porte, e têm como objetivos básicos proteger os meios de vida e a cultura dessas populações, e assegurar a reprodução social e o uso sustentável dos recursos naturais da unidade.

A Reserva Extrativista é de domínio público, com uso concedido aos extrativistas em regulamentação específica; de acordo com o que dispõe a lei, as áreas particulares incluídas em seus limites devem ser desapropriadas. A RESEX é gerida por um Conselho Deliberativo, presidido pelo órgão responsável por sua administração e constituído por representantes de órgãos públicos, de organizações da sociedade civil e dos povos tradicionais residentes na área, conforme disposto no regulamento e no ato de criação da unidade.

A visitação pública é permitida, desde que compatível com os interesses locais e de acordo com o disposto no Plano de Manejo da área. A pesquisa científica é permitida e incentivada, sujeitando-se à prévia autorização do órgão responsável pela administração da unidade, às condições e restrições estabelecidas por este e às normas previstas em regulamento.

O Plano de Manejo da unidade precisa ser aprovado por seu Conselho Deliberativo. São proibidas a exploração de recursos minerais e a caça amadorística ou profissional. A exploração comercial de recursos madeireiros só será admitida em bases sustentáveis e em situações especiais e complementares às demais atividades desenvolvidas na RESEX, conforme o disposto em regulamento e no Plano de Manejo da unidade. Há uma divisão (popular) das Reservas Extrativistas em Reservas de Floresta e as Reservas Marinhas.

\section{AS RESERVAS EXTRATIVISTAS MARINHAS (REM)}

As REMs foram instituídas pelo poder público, visando à delimitação de territórios marinhos como propriedade exclusiva de grupos específicos, que não gozavam de legitimidade perante as instâncias legais. Na criação das REMs, o poder público, ao determinar áreas até então consideradas de livre 
acesso, transformando-as em espaços onde os recursos são explorados de forma comunitária por pescadores artesanais organizados, reconhece o direito consuetudinário desses grupos sobre territórios marinhos (onde se incluem territórios fronteiriços entre terra e mar como mangues e estuários), as formas de arranjos e representações simbólicas de tradição pesqueira secular e exclui os não comunitários do aproveitamento dos recursos do mar nas áreas delimitadas (Chamy 2002: 2).

As reservas estão localizadas em terrenos exclusivos da Marinha, e, portanto são federais (Chamy 2002). As áreas de livre acesso passam a ser delimitadas, e o uso do espaço costeiro regulamentado. Tais medidas foram transformadas através de arranjos de direitos de propriedade (Ostrom \& Mc Kean 2001).

A primeira REM com a finalidade de unir preocupações preservacionistas e prerrogativas dos povos tradicionais foi criada em 1992, fora dos limites da Amazônia - a REM de Pirajubaé, no Estado de Santa Catarina (Cecca 1997).

Na Região Norte, até 1994, foram criadas nove RESEXs: Ciriaco, no Maranhão; Extremo Norte do Tocantins, em Tocantins; Quilombo do Frexal, no Maranhão; Mata Grande, no Maranhão; Alto Juruá e Chico Mendes, no Acre; Rio Cajari, no Amapá; Rio Ouro Preto, em Rondônia. As resexs existentes na área litorânea do estado do Pará foram em 2008 reunidas na Central das Associações dos Usuários das Reservas Extrativistas Marinhas do Pará (CAUREM) a fim de somar esforços para agilizar a concessão dos crédi- tos e a contemplação dos programas do governo e políticas públicas, assessoradas pelo apoio e experiência do Conselho Nacional de Populações Extrativistas (antigo Conselho Nacional de Seringueiros - CNS).

A partir do surgimento deste tipo de Unidade de Conservação, o governo intensificou a criação de instituições e instrumentos legais direcionados aos extrativistas como a implantação de políticas públicas, programas de crédito e assistência técnica tanto âmbito federal como estadual para os povos extrativistas.

\section{A REM CAETÉ-TAPERAÇU}

A REM Caeté-Taperaçu, localizada no município de Bragança, nordeste do estado do Pará, cerca de $200 \mathrm{~km}$ a sudeste da foz do estuário amazônico, foi criada em 20 de maio de 2005 (Peres 1999). A região nordeste paraense é a área de ocupação mais antiga do estado, situando-se entre as áreas mais impactadas pela ação humana do litoral amazônico; por suas características geográficas e pelos impactos gerados através das atividades do turismo, agricultura e pesca, é considerada uma área de alto risco ambiental (MMA 1996).

Região rica em manguezais, comporta cerca de 28,3\% (389.400 ha) dos manguezais brasileiros. Estes ecossistemas oferecem condições ideais para o desenvolvimento de inúmeros organismos, que os procuram para a sua proteção, alimentação e reprodução, provendo assim alimento abundante, o que é importante para a fixação de grupos hu- 
manos próximos, ou mesmo contíguos a esses meios (Senna et. al. 2002), o que configura diversos atores sociais, principalmente pelas populações das áreas costeiras e estuarinas, uma vez que dispõe de uma abundância de recursos naturais (Oliveira 2004). Bragança é um dos municípios mais ricos do nordeste paraense, banhado pelo rio Caeté (Figura 1).

O município é constituído de várias vilas e/ou comunidades situadas, principalmente, na estrada que liga Bragança a Ajuruteua, em áreas amplas de bosques de mangue. Dentre estas, podemos citar Vila Bonifácio, Bacuriteua, Castelo, Tamatateua, Caratateua, Acarajó Grande, Treme, Vila que era, Vila do Meio, Taperaçú-Porto, Ajuruteua, Porto do Campo, Cajueiro, Serraria, entre outras, possuindo a península bragantina pouco mais de 21 comunidades com aproximadamente 13.000 habitantes.

Com cerca de $180 \mathrm{~km}^{2}$ de ecossistemas manguezais, as populações humanas que aí vivem usam direta ou indiretamente os recursos deste ecossistema. Os mais relevantes para o contexto econômico, ecológico e social são o caranguejo, os peixes, as árvores, espaço ou terras em geral (Glaser et al. 2005).

Cerca de 40\% das famílias extraem parcial ou totalmente a sua renda da coleta do caranguejo (Ucides cordatus), e 60\% da captura são de peixes. Os sistemas de produção pesqueira são artesanais e caracterizam-se pela variedade de técnicas de captura e de micro ambientes explorados, como, por exemplo, as cabeceiras de rios, igarapés, praias, restingas, foz de rios, baias, mar aberto e os próprios manguezais (Oliveira 2004). A vida dessas populações, portanto, tem sua base de sustentação social e econômica nas relações com o mar, através de pesca tradicional, de coleta e do extrativismo, com métodos e técnicas de trabalho eminentemente simples. Sua economia é simples, com base na mãode-obra familiar (Furtado 2001).

Há cerca de 18 anos, Maneschy (1995) já evidenciava uma tradição pesqueira principalmente como base de subsistência na vila de pescadores de Ajuruteua: captura de frutos do mar, principalmente o pescado, mas também o camarão e o caranguejo, bem como o sururu (ou mexilhão) eram os recursos já explorados. ${ }^{1}$

A criação da Reserva Extrativista Marinha de Caeté-Taperaçu (Figura 2), no Município de Bragança, Estado do Pará, abrangendo uma área de aproximadamente $42.068,86$ ha pelo Decreto de 20 de maio (Brasil 2005), veio intensificar a necessidade de mediação, diálogo e real conhecimento da dinâmica dos recursos como bens públicos assegurados pela Constituição Federal, pois neste tipo de unidade de conservação evidencia uma necessidade de maior participação popular e comunitária nas decisões e implementações, para que a existência e a integridade da RESEX e das populações humanas locais sejam perpetuadas.

A RESEX bragantina foi considerada uma RESEX de segunda geração, pois apesar das reivindicações feitas há anos pelos moradores em relação aos seus modos de vida e recursos de sobrevivência, a implantação desta unidade 


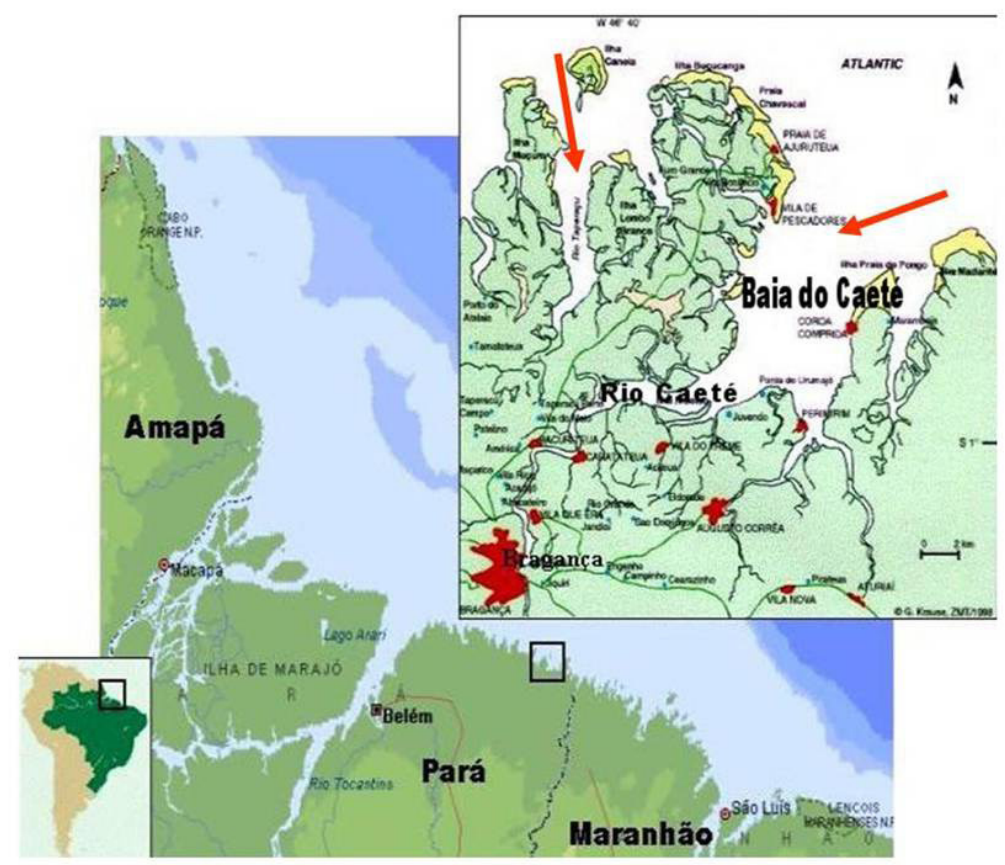

Figura 1 - Área de estudo, na região bragantina, com (a) destaque para os rios Caeté e Taperaçu (Adaptado de Peres 2011) e (b) área de abrangência da Reserva Extrativista Marinha de Caeté-Taperaçu. (Fonte: http://www.mma.gov.br).

de conservação se deu a partir de uma oferta oficial do poder público federal. As reservas de primeira geração foram criadas no final da década de 1980 , em um cenário de lutas e conflitos sociais, principalmente de natureza fundiária.

A criação da REM bragantina, na realidade, surgiu como uma oferta circunstancial do Governo Federal para atender os anseios das populações locais que evidenciavam a preocupação em garantir seus modos de vida e de produção, bem como a proteção de seus territórios. Assim, a partir do início da década de 1990, o Poder Público Federal fez surgir as chamadas reservas extrativistas de segunda geração, já que o Brasil por pressão internacional deveria provi- denciar uma ação que combatesse os desmatamentos na Amazônia (Glaser e Diele 2005). Como havia um clamor vindo da zona bragantina, houve então um somar de perspectivas e, após as reivindicações verbais por parte dos moradores bragantinos, passou-se a compor os trâmites burocráticos para conceber a criação desta UC.

Antes da implantação da RESEX, pesquisadores que atuaram na zona bragantina contribuíram para a elaboração do laudo biológico e sócio-econômico (etapas precursoras para a criação deste tipo de UC); além disso, alguns grupos de pesquisa em parceria com o Movimento dos Pescadores do Pará (MOPEPA), procuraram trabalhar o 

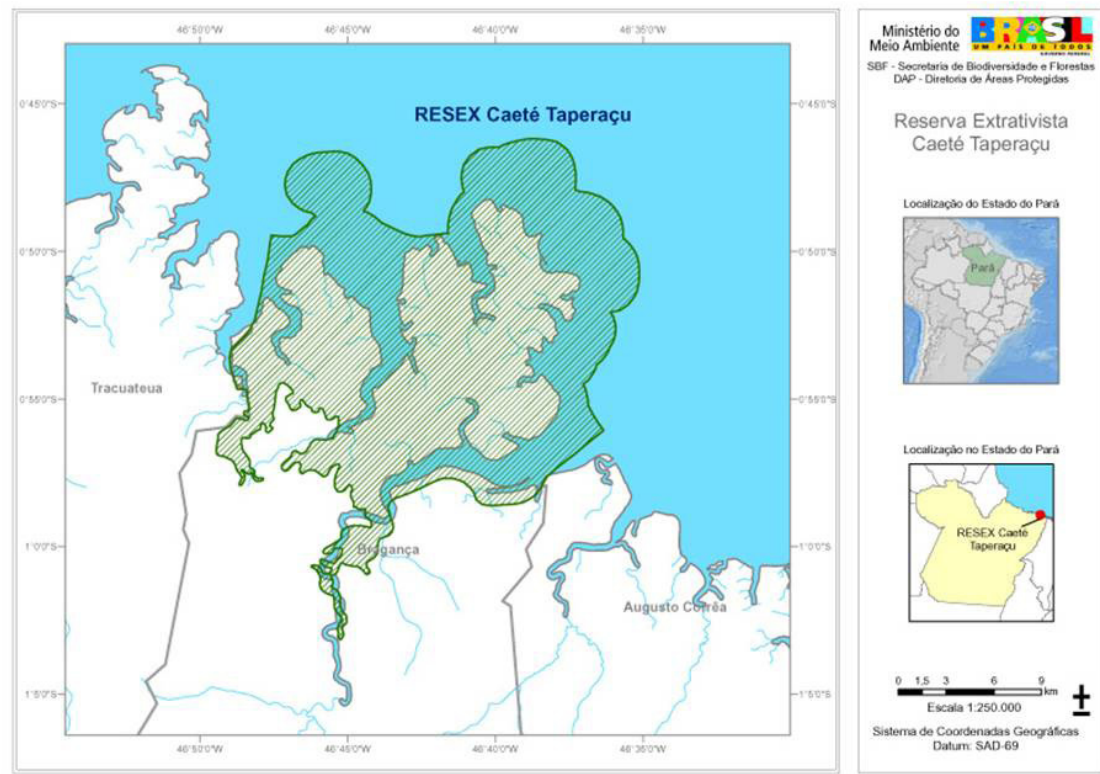

Figura 2 - Área de abrangência da Reserva Extrativista Marinha de Caeté-Taperaçu. (Fonte: http://www.mma.gov.br).

modelo de cogestão e o conceito de RESEX entre os moradores de algumas comunidades, utilizando para esta finalidade um recurso didático: uma cartilha elaborada conjuntamente entre o grupo sócio-econômico do programa MADAM (Mangroves Dynamics and Management Program $)^{2}$ e o MOPEPA, acima citado.

A concepção de RESEX inclusive iniciou com a discussão sobre a pesca predatória na região. A iniciativa dos comunitários de encontrar soluções para esta problemática $^{3}$ foi fortalecida a partir da inserção do IBAMA através do CNPT (Centro Nacional de Desenvolvimento Sustentado das Populações Tradicionais). Contudo, ainda era preciso que o poder público realmente se mani- festasse na demanda que recebe destas populações e nas próprias leis que ele mesmo elabora e implanta, muitas vezes por autores que não vivenciam o cotidiano dos povos a serem contemplados.

Uma coisa é discutir os direitos dos povos tradicionais nas unidades de uso sustentável, criadas pela legislação pertinente, na qual a maioria destas áreas foram implantadas e geridas sem qualquer consulta a sociedade e sem levar em consideração os direitos das comunidades mais diretamente atingidas; outra é partir de um consenso, de uma decisão compartilhada entre os povos tradicionais e os agentes ambientais públicos. Em geral, ocorre um verdadeiro embate entre o poder público local e povos tradicionais que 
ali habitam. Ambos defendem políticas de melhorias de condições de vida para essas populações, mas o que se verificava são as ausências dessas políticas ou, quando implementadas, a ineficácia marca as ações governamentais. Tal situação pode ser resultante do descaso intencional de quem está à frente dos órgãos públicos (prefeitura, secretarias municipais etc) ou pode ser consequência da ausência de práticas participativas pelos moradores dessa região. Assim, a exclusão da população no processo decisório e práticas políticas patrimonialistas impedem o desenvolvimento local nessa região (Cardoso s.d.).

Na região bragantina, Cabral, Armin e Glaser (2005) abordaram as políticas de desenvolvimento existentes para o setor pesqueiro artesanal e a presença do pescador na construção e implantação destas políticas. Analisaram a qualidade do capital social, os sistemas de organização social dos mesmos e já alertaram conclusivamente que a implementação das políticas públicas está prevista nos documentos e nas discussões das políticas de desenvolvimento do setor pesqueiro, porém na prática, não existiu consenso entre Estado e pescadores.

No que se refere à captura do caranguejo, por exemplo, está ainda submetida às leis que regulamentam a época do defeso dentro de um cronograma regional, homogeneizando períodos de reprodução e desova em diferentes pontos do grande litoral brasileiro. Mas a lei que regulamenta as especificidades do período reprodutivo das espécies situadas no litoral bragantino tem uma fragilidade em sua fiscalização, o que gera uma série de capturas irregulares por diversos atores sociais.

Segundo Glaser \& Diele (2005) a sustentabilidade biológica da captura do caranguejo não era ameaçada (a época) deste recurso, mas sim as condições econômicas e sociais: disfunções socioinstitucionais no âmbito individual ou domiciliar, como alcoolismo, evasão escolar, dependência dos tiradores de patrões/atravessadores e no âmbito social, conflitos sobre territórios de produção, métodos de coleta, além da deficitária organização e representatividade da categoria. Os tiradores de caranguejo vivem em condições de vida insatisfatórias, geralmente entrando na profissão com 15 anos, atrelados a este sistema e muitas vezes não tendo a oportunidade de escolarização.

\section{A ASSOCIAÇÃO DOS USUÁRIOS DA RESERVA EXTRATIVISTA MARINHA CAETÉ-TAPERAÇU - ASSUREMACATA}

Uma das etapas requeridas antes da implantação desta Unidade de Conservação foi a formação de uma associação representativa dos usuários da reserva. As associações em reservas extrativistas foram fruto da luta conjunta da categoria extrativista em prol de reivindicações coletivas. $\mathrm{Na}$ realidade geral das associações nas reservas já criadas, algumas conquistas foram alcançadas como o alavancamento da produção em algumas Unidades de Conservação, bem como agregação de 
valores a determinados produtos do extrativismo; concessão de créditos; abertura de novos mercados; conhecimento de novas tecnologias; implantação de políticas públicas na área de saúde, educação, comunicação, e concessão de infraestrutura a produção e vivência extrativista (GT Organização e Gestão $/ 2^{0}$ Congresso das Populações Extrativistas da Amazônia/CNS Belém 2009).

$\mathrm{Na}$ realidade bragantina, os interesses, direitos e deveres dos usuários, bem como a gestão local e comunitária passaram a ser mediados pela Associação dos Usuários da Reserva Extrativista Marinha Caeté-Taperaçu (ASSUREMACATA), como concessionária dos direitos de uso cedido pelo Estado. "As associações também passaram a ser responsáveis pela gestão das áreas e pelo controle sobre a utilização dos recursos, as quais, pelo contrato, ficam sob a fiscalização do poder público" (Allegretti 1994: 27).

A necessidade de associativismo levou à criação desta organização, cuja estrutura é formada por: 1) um presidente; 2) um vice-presidente; 3) primeiro e segundo secretários; 4) primeiro e segundo tesoureiros; 5) um Conselho Deliberativo; 6) o Grupo de Trabalho (GT) do plano de manejo e; 7) os comitês representativos das comunidades que constituem os polos Cidade, Bacuriteua, Acarajó Grande, Ajuruteua, Campo, Tamatateua, Caratateua, Treme. A essas se agrupam comunidades menores, situadas no entorno da área demarcada da Unidade de Conservação, a chamada área do entorno ou zona de amortecimento, onde em geral, são fixadas as residências dos beneficiários, usuários e demais moradores, e que corresponde a um raio de $10 \mathrm{~km}$, segundo a resolução do CONAMA n ${ }^{0}$ 13/90.

Inicialmente a associação funcionava em um prédio onde também se encontrava o escritório da Cáritas e o da Fazenda Esperança ${ }^{4}$ localizados no centro da cidade de Bragança. Depois passou a ter sede própria, cuja construção está situada próxima à entrada da vila Abacateiro, na estrada que liga a cidade de Bragança a Ajuruteua ${ }^{5}$ - a rodovia dos pescadores ou PA 458 - na periferia da sede do município. Edificada em alvenaria, a sede da associação possui alojamentos para hospedagem, sala de reuniões, cozinha, galpão e banheiros masculino e feminino, além de uma área central que será a futura instalação do auditório da associação.

O Conselho Deliberativo é formado pelo $\mathrm{ICMBio}^{6}$ que assume a presidência do mesmo, a executiva da associação, os representantes dos comitês, da Colônia de Pescadores Z-17 - Bragança, do Sindicato dos Pescadores Artesanais de Bragança, da Associação Movimento dos Pescadores do Pará (MOPEPA), Conselho Nacional das Populações Extrativistas (CNS), Sindicato dos Trabalhadores Rurais de Bragança - STR/Bragança, Igreja Católica/Diocese de Bragança/Pará, Igreja Evangélica/AssembleiaAssembleia de Deus - Bragança/PA, Sindicato dos Trabalhadores Artesanais de Bragança, Marinha do Brasil/Capitania dos Portos da Amazônia Oriental, Universidade Federal do Pará - UFPA, Tribu- 
nal de Justiça do Estado do Pará/Comarca de Bragança - TJPA, Secretaria de Ciência e Tecnologia da Amazônia - SECTAM, Empresa de Assistência Técnica e Extensão Rural do Pará EMATER-PA, Prefeitura Municipal de Bragança - PMB, Câmara Municipal de Vereadores de Bragança.Fazem parte do GT do plano de manejo, dois representantes da executiva da ASSUREMACATA, dois pesquisadores da UFPA, além de representantes de três comunidades locais.

Os comitês por comunidades foram constituídos por até seis representantes de cada polo formando o comitê local, escolhidos por eleição ou por indicação em seus locais de origem. As reuniões dos comitês, bem como do Conselho Deliberativo e do GT do plano de manejo, ocorreram sistematicamente na regularidade, nas justificativas e nas demandas previstas no regimento vigente, em reuniões ordinárias e extraordinárias.

Em assembleia, a executiva, junto com os comitês, decide e planeja as perspectivas e revê as regras no plano de uso dos recursos e espaços, as sanções, os arranjos para as escolhas coletivas, as atividades econômicas e os serviços sociais, decidem as formas de monitoramento pelos comunitários e os mecanismos de resolução de conflitos (Diegues 2001).

A associação ainda constituiu uma Secretaria de Mulheres, para congregar os interesses, as demandas e as reivindicações das moradoras e usuárias da reserva e estabeleceu o diálogo com outras lideranças de classe, como o Conselho Nacional de Populações Ex- trativistas da Amazônia (CNS); ${ }^{7}$ com o poder público local, estadual e federal; com instituições de pesquisa; com o Instituto Chico Mendes de Conservação da Biodiversidade (ICMBio) que é o órgão gestor das reservas extrativistas. A Secretaria de Mulheres, por sua vez, com o CNS Mulher, ${ }^{8}$ com o Movimento de Mulheres do Nordeste Paraense (MMNEPA), ${ }^{9}$ dentre outros. A liderança tem como escolha políticopartidária o Partido dos Trabalhadores (PT), se fazendo presente em passeatas, eventos e manifestações do partido.

A associação ainda se encarrega de fazer o cadastramento dos usuários, ${ }^{10}$ uma vez que, como as reservas também foram criadas como parte do programa de reforma agrária, ${ }^{11}$ os usuários, logo após a implantação deste tipo de Unidade de Conservação devem ser cadastrados a fim de serem contemplados com algumas ações do poder público, como os créditos de fomento e habitação, direito dos moradores das RESEXs e PAEs (Projetos de Assentamento Extrativista).

\section{AS PERCEPÇÕES DE DIFERENTES ATORES ACERCA DA REM CAETÉ- TAPERAÇU}

A percepção é a maneira como se vê, julga, conceitua, qualifica as coisas no mundo e em si mesmas. Segundo Merleau-Ponty (1966: 13 apud Josgrilberg 2006) são visões parciais [do mundo] porque se dão a partir da nossa situação em um dado campo perceptivo em que estamos no mundo. Uma criança, por exemplo, percebe o mundo antes de 
organizá-lo em categorias ou por uma linguagem constituída. Assim sendo, o mundo se revela para o sujeito que se dirige ao mundo. "Cada consciência é nascida no mundo e cada percepção é um novo nascimento da consciência". Os significados dados ao mundo não são meras elaborações intelectuais.

$\mathrm{Na}$ perspectiva de Husserl que Merleau-Ponty (1999) adotou, o mundo que conhecemos sabemos-o pela vivência, pela experiência singular; mesmo na ciência, "o universo por ela construído, é edificado sobre as nossas vivências e as nossas experiências, pois o mundo percebido é um mundo vivido, é uma experiência vivencial que é descrita e a ciência é apenas explicação ou análise desse mundo percebido".

As percepções de alguns atores (usuários, moradores e lideranças) acerca da RESEX, na experiência vivida desde a sua implantação ou a partir do momento em que tais atores (como por exemplo, os institucionais), começaram a atuar na criação da UC bragantina, são a seguir apresentadas.

Através de entrevistas semi-estruturadas, aos atores foi solicitado que falassem sobre a implantação e atual conjuntura desta Unidade de Conservação. Aos moradores, além de dados pessoais, informações sobre procedência e atividade familiar (se nascido ou morador antigo; se os pais e cônjuges eram da mesma comunidade, quais as atividades dos moradores), também foi perguntado se já tinham ouvido falar na RESEX, se sabiam qual o seu significado e suas finalidades e se algo havia mudado com a implantação da reserva no cotidiano da comunidade e nas atividades por eles executadas.

Para o presidente da ASSUREMACATA na gestão que se manteve até julho de 2009, as informações e esclarecimentos necessários aos comunitários acerca do modelo de cogestão de RESEX foram priorizados. Segundo ele, desde a pré-implantação da UC, várias visitas às comunidades locais foram realizadas a fim de esclarecer o que seria uma Reserva Extrativista Marinha, quais os benefícios seriam trazidos para as populações locais e para o ambiente.

Estas visitas ocorreram durante todo o processo de implantação da reserva, inclusive para a escolha participativa dos membros da associação; para a formação e a escolha dos comitês de cada comunidade; para a elaboração do plano de uso e, posteriormente, em qualquer demanda que as comunidades precisassem ser ouvidas ou informadas.

Já na condição de RESEX implantada, o presidente na época afirmou que o avanço mais substancial em sua opinião, ainda se restringia à elaboração do $\mathrm{Pla}$ no de Uso, precursor do atual Plano de Manejo, segundo ele, que aguarda apenas aprovação das instâncias competentes. Segundo ele, cerca de 70\% dos usuários da RESEX seguiram as recomendações previstas neste plano. Também relatou avanços no monitoramento das coletas de caranguejo, da extração de madeira para a construção dos currais, no beneficiamento do caranguejo, como uma ação conjunta entre os comunitários e o poder público. 
O presidente que assumiu a gestão a partir de agosto de 2009 é um pescador com 40 anos de idade, oriundo da praia do Picanço, localidade próxima à ilha de Canelas, situada no litoral bragantino. É casado, morador da comunidade Castelo, às margens do rio Taperaçu, barreira geográfica que também delimita a Reserva Extrativista. Traz na bagagem a atuação como liderança participativa, como denomina sua atuação na coordenação da catequese na igreja, quando era mais jovem na sua comunidade de origem. Relembra que a mãe ensinou a ele e aos irmãos a tudo repartir, ser generoso, porque ela era generosa, pois dividia com os vizinhos o alimento que conseguia para sua família comer. E é essa vivência que disse colocar em prática em sua liderança na associação.

A mãe nasceu na praia de Maiandeua, local farto de alimento, mas que com o tempo acabou, pois o local se tornou forte atrativo turístico. A família se viu obrigada a mudar-se para a praia do Picanço. Como tinha experimentado fartura, sentiu a necessidade de dividir o que tinha com os vizinhos; essa é a vivência e ideologia que disse pautar sua gestão na associação; disse que assumiu a ASSUREMACATA com esta linha de pensamento que sua mãe ajudou a construir, pois, em suas palavras, "ela me deu o exemplo". Admitiu que recebeu a associação com algumas pendências e problemas, tanto que precisou de um tempo para "tomar pé da situação" e se organizar. Apontou que um dos maiores desafios foi "conscientizar o povo da questão am- biental", pois admitiu que ainda falta muito "para o povo saber. O povo é acostumado com fartura. Antes tinha muito peixe, e a gente pegava muito peixe. Pegava os melhores, jogava fora o resto. Era um desperdício! Eu sempre fui pescador, não pegava caranguejo. Não tinha consciência, agora nós estamos sofrendo as consequências do passado".

Embora o desabafo, para ele "as coisas melhoraram”. Porém disse que a questão humana precisava melhorar, ou seja, precisava haver investimentos em educação através de cursos "para informar melhor as pessoas", inclusive com o auxílio de pesquisadores e profissionais nesta iniciativa. Observou ainda que o "pessoal da reserva precisa de políticas públicas que funcionem”, como exemplifica a necessidade do seguro defeso. $^{12}$

$\mathrm{O}$ vice-presidente (natural de comunidade do Treme, marcadamente coletora de caranguejo) foi pescador, trabalhou na roça, e "catou" caranguejo". Sobre a RESEX, ele disse que houve mudanças, pois surgiram novas parcerias, novos créditos chegaram (entenda-se novos itens de fomento) bem como o apoio dos governos federal e estadual. Informou que uma parceria com o primeiro poderia viabilizar a possibilidade da sede da associação passar a alojar um curso de capacitação em informática com duração de dois anos para jovens. "Os jovens são inteligentes, a gente entende como as coisas funcionam aqui, mas a gente precisa de apoio técnico".

Ele sugeriu o intercâmbio entre os saberes científicos e os tradicionais, ou 
seja, a soma do apoio técnico e o saber popular. "Em 2010, há intenção de terminar o prédio da sede" (o que não aconteceu). Os novos portões foram doação de um comerciante local, “já que falta apoio da prefeitura".

Ele diz que somente no início da implantação da reserva, a prefeitura auxiliou e isto só no que se refere à infraestrutura. Explicou que muitos diálogos não se estabelecem com a prefeitura devido às diferenças partidárias. "A gente também teme as negociações com a prefeitura, porque eles podem transformar associação em mote eleitoreiro, e a senhora sabe né? É poder de quem tem o dinheiro, e quem tem decide o que tem que fazer".

Segundo ele, o diálogo com o ICMBio, tem sido "muito bom" e complementa. "O gestor tem acompanhado a gente e tem mostrado que quer ajudar, estando presente em reuniões importantíssimas da RESEX". Com o consultor do PNUD $^{14}$ responsável pela elaboração participativa do Plano de Manejo na época, ele assegura que o contato tem sido também muito bom.

Sobre o Plano de Utilização ele disse que estava passando por ajustes e que cerca de $70 \%$ era o êxito já alcançado desde a sua criação. Sobre o cadastramento dos usuários e moradores exemplificou: "Para o cadastro, por exemplo, a pessoa tem que ser morador e usuário da RESEX, mas não basta ser só morador ou só usuário, tinha que ser num prazo de dois anos pelo menos para se cadastrar, agora a gente quer cinco".

Relatou que haviam três comunidades situadas no entorno da Unidade de Conservação que precisavam ser incluídas na abrangência, porque muitos dos seus moradores eram usuários da Reserva Extrativista. Seriam elas: Vila Nova, São Domingos e Jundiaí, já que as comunidades situadas no entorno até $10 \mathrm{~km}$ devem ser contempladas com os créditos, "porque tem usuário que é usuário, mas mora longe", justificou.

Sobre o papel da associação, ressaltou a importância do associativismo. "O pescador se preocupou com o ofício, mas não com a organização". Referiu-se ao fato de que havia ainda muitos trabalhadores que não eram registrados nem no Sindicato dos Trabalhadores Rurais. "Nós aqui na associação, encaminhamos o pescador, o caranguejeiro, os extrativista até para o INSS".

Como resultados alcançados desde que passou a vigorar o plano de uso, cita "os caranguejeiros não esquartejam mais os animais. Há o respeito ${ }^{15}$ pela condurua (denominação local da fêmea do caranguejo). Houve redução do desmatamento do mangal e a proibição do uso da fuzarca". ${ }^{16}$ A proibição de uso deste artefato de pesca foi um grande aprendizado para ele, "a fuzarca, pega peixe grande e pequeno e o desperdício é grande. Antes eu não tinha essa consciência. Hoje graças a Deus eu tenho". E ainda desabafou: "Professora! O pessoal do Treme aprendeu a pegar caranguejo. A pegar direito. Porque antes pegava de qualquer jeito, sem respeitar a natureza, e também o ofício desgasta a pessoa, impede de crescer, a pessoa não pode estudar".

$\mathrm{O}$ vice-presidente mudou rapidamente 
de assunto para mostrar uma caixa plástica, tipo caixa-arquivo chamada de "caixa de denúncia", uma iniciativa do ICMBio para possibilitar a qualquer comunitário fazer suas denúncias anônimas ou não, acerca de possíveis impactos ou conflitos na reserva.

Esta iniciativa, segundo a liderança da ASSUREMACATA e o gestor do ICMBio, auxiliado e muito nas ações de fiscalização e gerenciamento da reserva. Os depositantes não precisariam se identificar no ato da denúncia muito menos assinar a autoria da mesma. Assim, a iniciativa poderia ser anônima, resguardando a integridade de cada denunciante. Em função de alguma irregularidade a ASSUREMACATA pode ser acionada através dos representantes dos comitês. A associação juntamente com o ICMBio decide e toma as providências cabíveis com base no que é previsto no plano de uso e na legislação ambiental vigente mediante a avaliação e parecer de seu Conselho Deliberativo.

Ainda o vice-presidente disse que os comitês assessoravam, mas como alguns eram lideranças políticas, em algumas comunidades traziam por conta de divergências partidárias, problemas de relacionamento local. "Mas... a comunidade é quem escolhe, julga e tira os representantes do comitê". Sobre a mudança de gestão desabafou "a transição trouxe problemas de desconfiança a ASSUREMACATA. Impediu maiores parcerias, mas a gente agiu com sabedoria, discernimento e estamos tentando contornar".

A gestão da reserva é feita por um órgão governamental, o ICMBio que na pessoa do gestor tem investido no planejamento efetivo para as ações na RESEX, bem como no intercâmbio com o conhecimento local. À época, o gestor era mestrando em Biologia Ambiental do Campus de Bragança, assim a gestão e a pesquisa passaram então, na ótica dele, a ser dois aspectos, desafiadores para conciliar, fundamentais "para desengessar a ação técnica nas RESEXs". Considera a situação da RESEX promissora em alguns aspectos e crítica em outros, e justifica este estado da Unidade de Conservação pelos meses de ausência institucional e pelo conflito de identidade vivido por um período sobre qual instituição recairia a responsabilidade pela gestão nas reservas: IBAMA, CNPT, e agora, o ICMBio.

A falta de pessoal, de infra-estrutura e de orçamento tem sido também, na óptica dele, um complicador para a implantação no passado da maioria das Unidades de Conservação na Amazônia, do ponto de vista do poder público e institucional. Os comunitários que já tiveram contato com o gestor têm-no em certo prestígio destacando aspectos relacionados ao seu dinamismo e ao fato de estar sempre próximo da executiva da ASSUREMACATA.

Sobre a concepção dos usuários acerca da RESEX, o gestor disse que a grande maioria associa a melhoria advinda da implantação deste tipo de Unidade de Conservação com a concessão dos créditos por parte do INCRA. E acrescenta que a falta de informação e o histórico da formação e implantação das políticas públicas no país colabo- 
raram para a compreensão equivocada de muitas situações (por exemplo, o que vem a ser a condição de usuário e morador $^{17}$ ), isso sem levar em consideração o jogo político e "eleitoreiro" que perpassa muitas ações.

A gestão da reserva também é um desafio, uma vez que a grande extensão de área, a falta de infraestrutura, de sinalização e de demarcação são obstáculos importantes, que devem aos poucos ser superados para a implementação de fato da UC. O fortalecimento do associativismo e da representatividade da participação popular de forma sistemática e com ações sérias e concretas dentro das demandas da RESEX são também metas desafiantes. Sobre o plano de manejo, ressaltou a necessidade à época de se formar um GT com diferentes atores institucionais para acompanhar o trabalho de quem está à frente desta árdua missão, o consultor do PNUD.

Já para um dos membros do comitê deliberativo da ASSUREMACATA, a percepção que tinha do contexto humano da Unidade de Conservação era que seus moradores, usuários e lideranças tinham o foco nos créditos do INCRA. Considerou relevante esta preocupação, porém para ele a questão ambiental deveria ocupar um lugar de destaque, pois esta sendo relegada ao segundo plano. A necessidade do apoio técnico era uma das motivações para sua atuação junto ao conselho gestor. E ainda destacou como muito importante o intercâmbio entre diferentes profissionais para assessorar as diversas ações na reserva.

Já em relação a alguns moradores em uma das comunidades no entorno da Unidade de Conservação, a maioria não sabia o que era uma RESEX: "até tinham ouvido falar, mas não sabiam o que significava ou diziam que sabiam, mas não conseguiam explicar". Aqueles que num passado recente auxiliaram ou tiveram contato com pesquisadores dentro do programa MADAM, ${ }^{18}$ associaram a reserva à proteção do meio ambiente, da pesca. Mas a maioria associava a reserva (o conceito) à concessão dos créditos de fomento.

Se algo havia mudado na realidade de suas comunidades, uma minoria afirmou que o ambiente estava mais preservado. Mas, a resposta mais frequente também estava relacionada aos itens de fomento com os quais os moradores tinham sido contemplados. Mesmo aqueles que atribuíram as melhorias à proteção do ambiente também se referiam aos créditos de moradia e habitação. Atribuíram à implantação da reserva a uma conquista do "governo Lula". Esta percepção foi a mais contundente nas falas presentes, tanto da liderança quanto dos comunitários.

A correlação entre mudança/prosperidade e itens de fomento/habitação concedidos pode ser um reflexo da história experienciada pelos povos, ${ }^{19}$ que há décadas habitam a região bragantina. Esta como um todo experimentou um declínio populacional no passado (Hebette \& Acevedo Marin 1979). Por várias décadas, a população bragantina tem sido formada por pequenos produtores de culturas ali- 
mentares, basicamente mandioca, milho e arroz, os quais eram cultivados para uso próprio e para abastecimento da capital através de circuitos de comercialização em que vigoravam as relações de troca desiguais entre produtos da roça e manufaturados, o que contribuiu para uma situação de pobreza material experimentada por estes pequenos produtores, agravada por uma estrutura agrária marcada pelo minifúndio, resultante do processo de divisão de lotes pelas gerações sucessivas.

Décadas de pobrezas, de ações mitigadoras equivocadas tanto oriundas do poder público como de atores institucionais, fizeram com que esta porção da região nordeste do estado experimentasse uma decadência, o que resultou numa situação de total pobreza, onde as condições de moradia e alimentação eram extremamente precárias.

Quando perguntados sobre que mudanças a implantação da RESEX havia trazido na maneira de realizar suas atividades, alguns referiram ao respeito dispensado aos caranguejos no período da andada, ${ }^{20}$ a não captura de peixes pequenos, ${ }^{21}$ a redução no desmatamento do mangal, a não usar rede malhadeira muito fina na pesca, ${ }^{22}$ bem como o timbó, nem jogar lixo no rio. Embora o período da andada seja referido como um período de não captura, e assinalado como um momento que precisa ser resguardado, pois é quando ocorre a reprodução da espécie, alguns moradores denunciam que, inclusive, crianças, adolescentes e adultos capturam durante este período "em que o caranguejo está se perdendo”.
Embora muitos digam que não ouviram falar no "Plano de Uso", ou nunca tiveram acesso ao mesmo, justificam a captura por uma questão de subsistência, algo que é previsto no texto do documento. "Na época do suatá, período de reprodução da espécie fica permitido a captura somente para a própria alimentação do tirador e sua família, obedecendo aos limites máximos de 50 unidades por tirador cadastrado como usuário, não sendo permitida a comercialização do produto obedecendo a Legislação Ambiental" (Plano de Uso da Reserva Extrativista Caeté-Taperaçu). Disseram ter "noção" desse direito porque nas rodas de conversa "um vai dizendo pro outro".

O mangal é o lugar mais referido pelos moradores como o sítio necessário para ser protegido. Para Soffiati (2004), a destruição direta ou indireta do manguezal acarreta transformações sociais diretas ou indiretas que novamente incidem sobre o ecossistema, num ciclo que pode ser descendente ou ascendente.

\section{CONSIDERAÇÕES FINAIS}

As percepções acerca da reserva como unidade de conservação por parte dos moradores e usuários ainda são um processo e um conhecimento a ser construídos e partilhados. Apesar dos saberes presentes, transmitidos pela oralidade através das gerações, ainda eram equivocadas e dispersas as informações acerca da Reserva Extrativista e suas implicações, bem como dos direitos e deveres de seus moradores e usuários.

A necessidade do intercâmbio entre 
saberes e discussões sobre o uso da terra, do solo, da pesca, da coleta de caranguejo, do direito de propriedade, do gerenciamento de bens públicos dentro dos pressupostos assegurados por estas unidades de conservação ainda é um campo processual em construção. Considerado insipiente à época, o diálogo que promova entre as comunidades locais e outros atores sociais, o fluxo de informações necessárias para a consolidação do Plano de Uso, prerrogativa importante para a execução plena do Plano de Manejo da unidade.

Um dos espaços de competência que necessitariam ser desenvolvidos no seio desta UC, é o da informação aos quais os setores menos privilegiados da sociedade não têm acesso, uma vez que a informação constitui requisito essencial para a tomada de decisão e fonte básica do poder de pressão e demanda da sociedade sobre o poder público, uma vez que o estado exerce uma postura controladora.

Mas não é somente tornar a linguagem acessível para que termos técnicos usados pelos representantes dos órgãos públicos sejam entendidos e compreendidos, mas sim estabelecer e construir o diálogo levando em conta saberes distintos, embora este por vezes seja comprometido por racionalidades e sensibilidades diferentes o que configura percepções diferentes, níveis de linguagem diferentes, pois há uma diferença do olhar dos técnicos sobre os recursos naturais daquele compartilhado pelas populações tradicionais.

Para Devos et. al. (2009: 4) a transposição dos saberes científicos no âmbito das práticas cotidianas dos indivíduos e/ou grupos sociais é um fenômeno complexo "uma vez que tais saberes necessitam se configurar como um saber local para atingir a concretude das formas de interação dos diferentes grupos humanos com o ambiente que o circunda".

Em outras palavras, os saberes precisam circular para que o diálogo comece a se compor. Embora tradicionalmente o que se tem visto nas ações mediadas por projetos ambientalistas ou dentro da própria ciência ambiental, são as intervenções impositivas e negociadas nos grupos humanos, levando em consideração apenas a visão utilitarista de uso e exploração dos recursos naturais, sem levar em conta, as especificidades do lugar, os arranjos locais estabelecidos entre os indivíduos e a estrutura social (Rocha 2000).

Assim, urge uma "negociação" de uma realidade socioambiental entre dimensões éticas distintas (Cardoso de Oliveira \& Oliveira 1996) a partir da justaposição de tais saberes científicos e práticas cotidianas. Como fazer isto, é um desafio e um espaço de competência a ser formado (Devos et. al. 2009: 4).

As mudanças observadas junto à RESEX Caeté-Taperaçu, considerando as finalidades para as quais este tipo de UC foi criada (principalmente no que diz respeito à proteção aos modos de vida das populações humanas locais e ao ambiente), durante os anos transcorridos desde sua implantação ainda são pouco perceptíveis, uma vez que o processo de implantação requer adaptações e o estabelecimento e intensificação do diálogo entre os atores sociais envolvidos: comunitários, lideranças, autoridades ambien- 
tais e o poder público.

Além disso, em outras experiências com o modelo de Reservas Extrativistas tem sido evidente os limites do mesmo, como, por exemplo, a incapacidade de abranger áreas proporcionais à escala dos processos biológicos; dificuldades na gestão, na manutenção e, principalmente, incompatibilidades no convívio intra e intergrupal de todos os atores sociais envolvidos na implantação da reserva, devido ao fato das Unidades de Conservação, quase na totalidade das vezes, significarem restrições às populações que historicamente habitavam as regiões em que são implementadas, pois enquanto uma forma de ordenamento territorial, o desafio primeiro é conciliar as decisões do Estado com as expectativas dos extrativistas.

A questão ambiental que norteia a criação das diversas unidades de conservação previstas no SNUC representa um desafio de grande complexidade, uma vez que se trata de um processo em construção. Percebe-se que o destaque quanto aos "sucessos" relacionados à implantação da RESEX Marinha Caeté-Taperaçu, refere-se quase na totalidade das falas dos interlocutores aos itens de fomento concedidos pelo Estado. Essa, portanto, é a mudança alardeada e visualizada por aqueles que vivem na área protegida. Quando se destaca o uso e o manejo dos recursos naturais, as práticas pouco ou quase nada foram alteradas desde o surgimento da Unidade de Conservação. Nota-se que quanto aos comunitários, poucos conhecem as regras previstas no Plano de Uso ou sabem do que se trata esse documento.

Assim, além da fraca participação na gestão que, necessariamente, deveria ser compartilhada - uma vez que se concebe de forma efetiva a participação da população local neste tipo de gestão e as evidências mostram que não ocorre desta maneira - pois a falta de informação acerca do que vem a ser o modelo de cogestão das RESEXs tendem a reduzir a participação dos comunitários nos processos decisórios relacionados às formas de manejo cogerido da UC.

Por outro lado, a questão orçamentária implica uma celeuma quanto à gestão da RESEX, tornando-se mais crítica nas etapas necessárias a elaboração e a execução do Plano de Manejo. Assim, é necessário o cumprimento do papel do poder público na concessão de recursos e incentivos, a necessidade de assessoramento técnico requerido pelos extrativistas, e a concepção de ambos os lados na direção de uma gestão compartilhada, pois somente assim este modelo de Unidade de Conservação poderá mostrar-se viável no que se refere à atenção e respeito aos direitos humanos e a conservação dos ambientes ameaçados.

Chávez (2002: 4) observa que "uma opção antropológica deve favorecer uma avaliação dos fatores ou elementos políticos e culturais que estão impedindo ou que podem favorecer a consolidação destes modelos". Sendo assim, a vulnerabilidade do modelo de co-gestão RESEX não reside na insustentabilidade econômica, muito menos terá como resolução, ações ou projetos produtivos isolados. Tal vulnerabilidade, no caso da RESEX Marinha 
Caeté-Taperaçu é verificável pela ausência de conhecimento sobre as expressões culturais e as especificidades quanto ao ethos local, indo na direção da defesa do território que incorpore a "territorialidade da reserva".

Este modelo de UC e de gestão obviamente teria que apelar a relevância da partilha e o diálogo de saberes, com a real incorporação do conhecimento local ao conhecimento cientifico, como diz Chávez dentro de uma perspectiva transformativa, aberta às novas propostas e conhecimentos, porém orientada para uma integração intrareserva, ou seja, no contexto de todos os atores envolvidos. Tanto a sua implementação quanto a sua evolução e perspectivas futuras estão condicionadas às transformações diversas como a garantia da condição de permanência dos grupos humanos, sua reprodução social bem como a contrapartida do poder público com a implantação de políticas públicas contextualizadas são fatores determinantes.

Uma vez que os técnicos gestores estatais percebem os grupos humanos que vivem junto às RESEXs de forma homogênea, há emergência de reconhecer as diversidades que constituem essas experiências locais de viver e praticar os lugares, o que sugere uma nova racionalidade ambiental baseada especialmente nas aspirações e nas estratégias produtivas das comunidades locais. Como propõe Rocha (2001), ou seja, buscar na sociedade de cada "lugar" estratégias que aliem às expectativas de desenvolvimento e a disposição de cada comunidade no que se refere ao uso dos recursos naturais a sua volta dentro de regras compartilhadas. Nesse aspecto, se as experiências acumularam mais frutos do que ônus em diversos pontos de vista, o modelo de RESEX pode ser um referencial útil para se pensar outras categorias de conservação de uso sustentável em regiões diversas da Amazônia.

\section{NOTAS}

${ }^{1}$ Segundo Carvalho (2004), os povos tradicionais entre tantos outros grupos lutam por legitimar formas de uso dos bens ambientais, de acesso a eles e de convivência e interação com o ambiente, assim como dos saberes correspondentes, por serem de extrema relevância para a sobrevivência social, cultural e biológica destas populações.

2 MADAM (Mangrove Dynamics and Management - Manejo e Dinâmica em Áreas de Manguezais) foi um programa de cooperação científica entre Brasil e Alemanha, que surgiu após as discussões da Conferência Rio 92 para o Desenvolvimento do Meio Ambiente sobre a necessidade de implementar pesquisas que ajudassem a proteger os ecossistemas naturais, dentre eles os manguezais. Entrou em vigor em 1995 e encerrou suas atividades em 2005. Às vésperas da implantação da reserva extrativista, o programa MADAM, que já vinha realizando estudos desde 1995 na península bragantina, assegurou pesquisas e ações no sentido de auxiliar os comunitários acerca do modelo de co-gestão da área protegida que seria implantado (Glaser et al. 2005). Tanto que muitas informações que respaldaram os laudos e levantamentos socioeconômicos partiram das pesquisas multi e interdisciplinares deste programa.

${ }^{3}$ A Constituição Brasileira, no seu Artigo 225, declara que "todos têm direito ao meio 
ambiente ecologicamente equilibrado, bem como de uso comum do povo e essencial à sadia qualidade de vida, impondo-se ao poder público e à coletividade o dever de defendê-lo e preservá-lo ás presente e futuras gerações" (Brasil 1988). Ao afirmar que todos têm direito ao meio ambiente ecologicamente equilibrado a Constituição define que a titularidade deste direito é assegurada ao indivíduo como também a coletividade, e o dever de defendê-lo e preservá-lo é uma obrigação do Estado, dos indivíduos e da sociedade, colocando num mesmo patamar de direitos e obrigações o público e o privado, eliminando assim uma antiga dicotomia civilista (Benatti 1998).

4 Associação reconhecida pela Igreja Católica, que trabalha em diversos campos sociais no território nacional, principalmente na recuperação de jovens dependentes químicos.

${ }^{5}$ Pequena vila litorânea, localizada a 36 quilômetros da cidade de Bragança, banhada pelas águas do oceano Atlântico e cercada por vegetação de mangues.

${ }^{6}$ Passou atuar na REM em questão a partir de 2009.

${ }^{7}$ O CNS como um todo, ampliou sua ação auxiliando também as REMs, a partir de um anseio já manifesto no passado pelo próprio Chico Mendes, o qual alavancou a luta trazendo não só as reivindicações dos seringueiros, mas de outras categorias: os castanheiros, os coletores de açaí entre outros. Com o declínio da borracha, em função da implantação de outros projetos no Acre, os seringueiros se lançaram também em novas fontes de subsistência e geração de renda. Assim, o CNS ampliou, desde a origem, a base social dos produtores de látex para abranger um conjunto de trabalhadores rurais que inclui agricultores, colonos e ribeirinhos

${ }^{8}$ Secretaria dentro do CNS que tem como metas assegurar os direitos das mulheres como direitos humanos; o empoderamento da mulher como condição para o fortalecimento das comunidades e o fortalecimento institucional como necessidade básica para a realização de suas ações. Disponível em: http://www.extrativismo.org. $\mathrm{br} /$ index.php?option $=$ com_content\&task $=$ section\&id $=6 \&$ Itemid $=48$

${ }^{9}$ Movimento que representa e luta pelos Direitos e Singularidades da Mulher Paraense, mas precisamente da região nordeste do estado.

${ }^{10}$ Os dados do cadastro solicitados são: nome, endereço, estado civil, idade, ocupação, registro em instância competente relacionada ao ofício desempenhado e número de registro de documentos de identificação, além de dados socioeconômicos.

11 Em 2008, uma portaria interministerial estendeu aos moradores e usuários das unidades de conservação e reservas, o direito de gozar de benefícios semelhantes ao dos assentados da reforma agrária. Ratificou uma prática acertada entre os ministérios do Desenvolvimento Agrário e do Meio Ambiente que existia desde 2002.

${ }^{12} \mathrm{O}$ benefício é de um salário mínimo, pago pelo Ministério do Trabalho no período de reprodução da espécie que está sob o defeso, determinado por portaria do IBAMA.

${ }^{13}$ No sentido de coletar, capturar o animal e não retirar a "massa" do caranguejo.

${ }^{14}$ O Programa das Nações Unidas para o Desenvolvimento (PNUD) é a rede global de desenvolvimento da Organização das Nações Unidas, presente em 166 países. Seu mandato central é o combate à pobreza. Trabalhando ao lado de governos, iniciativa privada e sociedade civil, o PNUD conecta países a conhecimentos, experiências e recursos, ajudando pessoas a construir uma vida digna e trabalhando conjuntamente nas soluções traçadas pe- 
los países-membros para fortalecer capacidades locais e proporcionar acesso a seus recursos humanos, técnicos e financeiros, à cooperação externa e à sua ampla rede de parceiros (Fonte: http://www.pnud.org. $\mathrm{br} / \mathrm{pnud} /$ )

${ }^{15}$ Segundo Diegues (2001), o termo "respeito" pela natureza tem a conotação de proteção.

${ }^{16}$ Semelhante a um puçá, porém maior e fixo.

${ }^{17}$ Neste caso, o usuário é aquele que pode ou não ser morador local, mas que extrai recursos naturais e realiza práticas extrativistas.

${ }^{18}$ Embora as ações do Programa MADAM através do seu grupo da socioeconomia, tenham sido também no sentido de diagnosticar as condições para a implantação do co-manejo costeiro no modelo RESEX (Glaser \& Oliveira 2004) e junto com o Movimento dos Pescadores do Pará (MOPEPA) trabalhar a noção das reservas extrativistas, uma desinformação, certo desconhecimento é ainda observado. A ausência que persiste ainda de uma ação informativa sistemática contribui para a inexistência de um diálogo e informações desencontradas.

${ }^{19}$ A região bragantina passou por um declínio populacional (Hebette \& Acevedo Marin 1979) onde em muitas áreas do interior durante várias décadas, a população era composta de pequenos produtores de culturas alimentares obtidas para subsistência e para abastecer a capital através de circuitos de comercialização, onde vigoravam as relações de troca entre produtos da roça e manufaturados. Para esse conjunto de produtores ainda vigora uma situação de pobreza material agravada pela estrutura agrária do minifúndio, fruto do processo de divisão dos lotes pelas gerações sucessivas de agricultores (Maneschy, 1993), daí talvez explique a não mitigação da pobreza em tempos atuais, o que resulta na valorização da aquisição dos créditos do INCRA.
${ }^{20}$ Período de reprodução destes animais, também chamado de soatá ou suatá. Eles saem das tocas e podem ser facilmente capturados. Para proteger este período há uma portaria do IBAMA (Port. N0 1 de 19 de novembro de 2008) que determina os períodos em que todas as atividades relativas à captura, transporte, beneficiamento, industrialização, armazenamento e comercialização são proibidas.

${ }^{21}$ Peixes que atingiram maturação sexual. Peixes jovens. Em algumas espécies, é o tamanho e a maturação gonadal que definem a condição adulta.

22 Rede de pesca cujo diâmetro da malha é pequeno suficiente para capturar peixes muito jovens ou outros organismos aquáticos, que depois de capturados são descartados.

\section{REFERÊNCIAS}

Allegretti, M. H. 1994. Reservas extrativistas: Parâmetros para uma política de desenvolvimento sustentável na Amazônia, in $O$ destino da floresta: reservas extrativistas e desenvolvimento sustentável na Amazônia. Editado por R. Arnt, pp. 17-47. Rio de Janeiro: Relume Dumará.

Benatti J. H. 1998. Unidades de conservação e as populações tradicionais: uma análise jurídica da realidade brasileira. Novos Cadernos NAEA 2 (2).

Brasil. 2005. Decreto de 20 de maio de 2005. Dispõe sobre a criação da Reserva Extrativista Marinha de Caeté-Taperaçu, no Município de Bragança, no Estado do Pará, e dá outras providências. Diário Oficial da União, Brasília, p. 8, 23 de maio de 2005. Disponível em: <https://www.planalto.gov.br/ ccivil_03/_Ato2004-2006/2005/Dnn/ Dnn10531.htm>. Acesso em: 18 de outubro de 2005. Constituição (1988). Constituição 
da República Federativa do Brasil. Brasília, DF: Senado, 1988.

Cabral, N., M. Armin e M. Glaser. 2005. Políticas públicas, capital social e participação na pesca artesanal do nordeste paraense, in Gente, Ambiente e Pesquisa. Editado por M. Glaser, N. Cabral e A.L. Ribeiro, pp. $207-$ 222. Belém: NUMA/UFPA.

Cardoso, D. M. Texto produzido a partir da tese intitulada Processo Decisório de Políticas Públicas para o Desenvolvimento Local: Rio Arraiolos - Almeirim/Pará.Inédito.

Cardoso de Oliveira, 1. R. \& R. C. de Oliveira. 1996. Ensaios Antropológicos sobre Moral e Ética. Rio de Janeiro: Tempo Brasileiro, 188 p.

Carvalho, I. C. M. 2004. Educaşão Ambiental: a formacão do sujeito ecológico. São Paulo: Cortez.

Cecca. 1997. Unidades de conservacão da ilha de Santa Catarina. Florianópolis: Editora Insular.

Chamy, P. 2002. Reservas extrativistas marinhas: um estudo sobre posse tradicional e sustentabilidade. Anais do I Encontro da Associação Nacional de Pós-Graduação e Pesquisa em Ambiente e Sociedade - ANPPAS. Indaiatuba - SP. Disponível em: <www. anppas.org.br/gt/conhecimento_local/Paula\%20Chamy.pdf $>$ Acesso em: 01/10/2006.

Chávez M. G. G. 2002. Biodiversidade e Conhecimento Local: do Discurso a Prática Baseada no Território, in I Encontro Nacional de Pós Graduação e Pesquisa em Ambiente e Sociedade. Indaiatuba, São Paulo.

Cunha, F. D. R. E T. S. Santiago. 2005. Organização social e representatividade política dos tiradores de caranguejo no município de Bragança, in Gente, Ambiente e Pesquisa. Editado por M. Glaser, N. Cabral e A.L. Ribeiro, pp. 155-166. Belém: NUMA/UFPA.

Devos, R., A.P.M. Soares,A. L. C. Rocha, L. Carvalho, R. Ribeiro, V. Vedana. 2009.
Habitantes do Arroio: estudo de conflitos de uso de águas urbanas, risco, saúde pública e comunidades étnicas em Porto Alegre-RS". Disponível em: <http://www.ram2009.unsam.edu. ar/>. Acesso em 17/2/2010.

Diegues, A. C. 2001. Repensando e recriando as formas de apropriação comum dos espaços e recursos naturais, in Espaços e recursos naturais de uso comum. Organizado por A.C.C.Moreira, pp. 97-124. São Paulo: NUPAUB.

Furtado, L. 2001. Ocupação humana do litoral amazônico, in Ecossistemas Costeiros: Impactos e Gestão Ambiental. Organizado por M.T.Prost e A.C. Mendes. Belém: Museu Paraense Emílio Goeldi. 29-38.

Glaser, M. e R.S. Oliveira. 2004. Prospects for the co-management of mangrove ecosystems on the North Brazilian coast: Whose rights, whose duties and whose priorities? Natural Resources Forum 28: 224-233.

Glaser, M., N. Cabral, N. E A.L. Ribeiro (Orgs). 2005. Gente, Ambiente e Pesquisa. Belém: NUMA/UFPA.

Glaser, M. e K. Diele. 2005. Resultados assimétricos: avaliando aspectos centrais da sustentabilidade biológica, econômica e social da pesca de caranguejo, Ucides cordatus (Ocypodidae), in Gente, Ambiente e Pesquisa. Editado por M. Glaser, N. Cabral e A.L. Ribeiro, pp. 51-68. Belém: NUMA/UFPA.

Hébette, J. e R. E. Acevedo Marin. 1979. Colonização para quem? Belém: NAEA/UFPA.

Maneschy, M. C. 1995. Ajuruteua: uma comunidade pesqueira ameascada. Belém: Ed. da UFPA.

Merleau-Ponty, M. 1999. Fenomenologia da Percep̧̧ão. Tradução de Carlos Alberto Ribeiro de Moura, São Paulo, Martins Fontes.

Ministério do Meio Ambiente, dos Recursos Hídricos e da Amazônia Legal. 1996. Perfil dos estados litorâneos do Brasil: subsidio a implantação do Programa Nacional de Gerenciamento Costeiro. (Série Gerenciamento). 
Oliveira, F. P. 2004. Avaliação dos impactos sócio-ambientais de projetos de extensão no litoral bragantino - Bragança - Pará. Dissertação de Mestrado. Programa de Pós-Graduação em Ecologia de Ecossistemas Costeiros e Estuários, Universidade Federal do Pará, Bragança-Pará, Brasil.

Oliveira, R. C. e L. R. C. Oliveira, 1996. Ensaios antropológicos sobre moral e ética. Rio de Janeiro: Tempo Brasileiro.

Josgrilberg, F. B. 2006. A fenomenologia de Maurice Merleau-Ponty e a pesquisa em comunicação. Revista Fronteiras 3: 223-232. <http://revcom.portcom. intercom.org.br/index.php/fronteiras / article/view/3137/2947>. Acesso em 29/09/2010.

Ostrom, E. e M. A. Mc Kean, 2001. Regime de propriedade comum em florestas: somente uma relíquia do passado?, in Espaço e Recursos Naturais de Uso Comum. Organizado por A.C. Diegues e A.C. Moreira, pp. 79-96. São Paulo: NUPAUB/USP.

Peres, A. C. 1999. A comunidade zooplanctônica em um canal de maré no estuário do rio Caeté, Bragança (Pará, Brasil). Dissertação de Mestrado. Programa de Pós-Graduação em Zoologia, Universidade Federal do Pará, Belém, Brasil.

Peres, A. C. 2011. Estudo Antropológico de uma comunidade no entorno da Reserva Extrativista Marinha Caeté-Taperaçu (Bragança-ParáBrasil). Tese de Doutorado. Programa de Pós-Graduação em Ciências Sociais, Universidade Federal do Pará, Belém, Brasil.

Rocha, A.L.C. 2000. Nas trilhas de uma bioetnodiversidade: a questão do olhar do outro e seus desdobramentos na construção dialógica das ciências ambientais. Porto Alegre: Instituto Antropos.

Rocha, J. M. A. 2001. Gestão dos Recursos Naturais: Uma perspectiva de Sustentabilidade Baseada nas Aspirações do Lugar.
Estudo \& Debate 7(1 e 2): 167-188.

Senna, C., C. F. Mello, e L. G. Furtado. 2002. Impactos naturais e antrópicos em manguezais do litoral nordeste do Estado do Pará, in Gente e ambiente no mundo da pesca artesanal. L. G. Furtado e H.D.A.B. Quaresma. Belém: Museu Paraense Emílio Goeldi. 209-238.

Soffiati Netto, A. A. 2004. Da mão que captura o caranguejo à globalização que captura o manguezal, in Anais do II Encontro da Associação Nacional de Pós-Graduação e Pesquisa em Ambiente e Sociedade. Indaiatuba, São Paulo.

Recebido em 15/05/2013.

Aprovado em 31/07/2013. 